\title{
Frequency and correlates of malaria over-treatment in areas of differing malaria transmission: a cross-sectional study in rural Western Kenya
}

\author{
Frankline M Onchiri ${ }^{1,2^{*}}$, Patricia B Pavlinac' ${ }^{1}$ Benson O Singa ${ }^{2}$, Jacqueline M Naulikha ${ }^{2,3}$, Elizabeth A Odundo ${ }^{8}$,
} Carey Farquhar ${ }^{1,5,6}$, Barbra A Richardson ${ }^{4,5,7}$, Grace John-Stewart ${ }^{1,3,5,6}$ and Judd L Walson ${ }^{1,3,5,6}$

\begin{abstract}
Background: In 2010, the World Health Organization shifted its malaria guidelines from recommending the empiric treatment of all febrile children to treating only those with laboratory-confirmed malaria. This study evaluated the frequency and predictors of malaria over-treatment among febrile malaria-negative children in Kenya.

Methods: Between 2012 and 2013, 1,362 children presenting consecutively with temperature $\geq 37.5^{\circ} \mathrm{C}$ to Kisii and Homa Bay hospitals were enrolled in a cross-sectional study evaluating causes of fever. Children were screened for malaria using smear microscopy and rapid diagnostic tests and managed according to standard of care at the hospitals. The frequency of anti-malarial prescriptions among children with laboratory-confirmed malaria negative children (malaria over-treatment) was determined; and clinical and demographic correlates of overtreatment evaluated using logistic regression. Because of differences in malaria endemicity, analyses were stratified and compared by site.

Results: Among 1,362 children enrolled, 46 (7\%) of 685 children in Kisii, and 310 (45.8\%) of 677 in Homa Bay had laboratory-confirmed malaria; $\mathrm{p}<0.001$. Among malaria-negative children; 210 (57.2\%) in Homa Bay and 45 (7.0\%) in Kisii received anti-malarials; $p<0.001$. Predictors of over-treatment in Homa Bay included $\geq$ one integrated management of childhood illness (IMCl) danger sign ( $a \mathrm{OR}=8.47 ; 95 \% \mathrm{Cl}$ : 4.81-14.89), fever lasting $\geq$ seven days (aOR $=4.94 ; 95 \%$ $\mathrm{Cl}: 1.90-12.86)$, and fever $\geq 39^{\circ} \mathrm{C}\left(\mathrm{aOR}=3.07 ; 95 \% \mathrm{Cl}\right.$ : 1.58-5.96). In Kisii, only fever $\geq 39^{\circ} \mathrm{C}$ predicted over-treatment $(\mathrm{aOR}=2.13 ; 95 \% \mathrm{Cl}: 1.02-4.45)$.
\end{abstract}

Conclusions: Malaria over-treatment was common, particularly in Homa Bay, where the prevalence of malaria was extremely high. Severe illness and high or prolonged fever were associated with overtreatment. Overtreatment may result in failure to treat other serious causes of fever, drug resistance, and unnecessarily treatment costs.

Keywords: Malaria, Laboratory testing, Over-treatment

\section{Background}

Malaria is a leading cause of morbidity and mortality among children in sub-Saharan Africa. The most well recognized sign of malaria infection is fever, which accounts for over $30-50 \%$ of all paediatric hospital visits in sub-Saharan Africa [1]. Historically, international guidelines recommended presumptive treatment of malaria in febrile children in endemic areas, as diagnostic tools

\footnotetext{
* Correspondence: fonchiri@gmail.com

'Department of Epidemiology, University of Washington, 325 Ninth Avenue, Box 359909, Seattle, WA 98104, USA

${ }^{2}$ Kenya Medical Research Institute, Centre for Clinical Research, Nairobi, Kenya Full list of author information is available at the end of the article
}

were infrequently available and cost prohibitive and malaria-attributable mortality that would occur if treatment was delayed was high [2]. Following considerable declines in malarial transmission in many parts of Africa, including in highly endemic areas [3-5], the increased recognition of the importance of life-threatening non-malaria fevers [6-8] and the wide availability of cheap and highly sensitive rapid diagnostic tests (RDTs), the World Health Organization released new malaria treatment guidelines in 2010 that recommend limiting treatment to laboratory-confirmed malaria [9]. While many countries, including Kenya, have adopted these guidelines with subsequent improvements in 
malaria case-management practices [10], a considerable proportion of febrile patients still continue to be treated for malaria despite negative laboratory test (over-treatment) [10-12].

Malaria overtreatment may result in the failure to treat other serious causes of fever, particularly blood stream infections [7,8]. Mortality among children treated for malaria is over two-fold higher in malarianegative children than in children with laboratoryconfirmed malaria, often as a result of untreated bacterial infections $[7,8,13]$. Additionally, malaria overtreatment can lead to the emergence of drug resistance, unnecessary adverse drug effects, increased treatment costs, and reduced quality of care $[14,15]$. Because of the serious potential consequences of malaria overtreatment, it is important to understand why some children are inappropriately treated with anti-malarials. This information will inform fever management and may improve understanding of guideline adherence in low-resource settings.

\section{Methods}

Study design, sites, and population

This was a cross-sectional study nested within an ongoing surveillance study of febrile illnesses among children at Kisii Provincial Hospital and Homa Bay District Hospital, both in Western Kenya. These hospitals are situated in areas with historically different malaria endemicity: Kisii is hypo-endemic with annual entomologic inoculation rate (EIR) of $<1.5$ infectious bites per person per year. Homa Bay historically has been holo-endemic with EIR of $\geq 300$ infectious bites per person per year $[16,17]$, although malaria prevalence declined by over $50 \%$ from 2003 to $2007[4,5]$ but then reversed to levels observed in 2003 [18]. Children ages six months to 15 years presenting with axillary temperature $\geq 37.5^{\circ} \mathrm{C}$ at the out-patient departments (OPD) were approached consecutively for enrolment and almost all were enrolled in OPD (98\%). A minority of study children $(<2 \%)$ were admitted to the wards directly from OPD and enrolled from the inpatient ward. Eligible children included those whose accompanying parents/guardians consented to HIV counseling and study participation of their children. Because this study was nested within a large surveillance study of febrile illnesses, data from all children enrolled at the time (April 2012 - November 2013) of analysis presented in this paper were used. The study was approved by the Ethical Review Committees of both the University of Washington and the Kenya Medical Research Institute.

\section{Study and hospital clinical staff}

Clinical staff at the study sites consists of clinical officers and registered nurses with three years of medical training and licensed to independently diagnose and treat diseases, including ordering and interpreting laboratory tests. There are very few medical doctors available for direct clinical care. The new malaria "test and treat" policy was adopted by the Kenyan Ministry of Health in 2011, and subsequently health workers received in-service malaria case-management training [11]. However, structured monitoring and supervision of malaria treatment and treatment practices are not routinely available. Study clinicians/nurses worked together with hospitals' clinical staff and assisted with the diagnosis and treatment of patients regardless of their eventual study participation statues.

\section{Training}

Study staff was trained on enrolment criteria, consent, clinical and laboratory procedures, use of integrated management of childhood illness (IMCI) syndromic management algorithms, and assessment of danger signs. Because the parent study was a cross-sectional study aimed at understanding bacterial etiologies of fever, the study protocol did not stipulate standardized treatment protocols for malaria and clinicians managed sick children according to the standard of care practices at the hospitals.

\section{Data collection}

During screening and enrolment, study clinicians and registered nurses systematically captured comprehensive information regarding sociodemographics, anthropometric characteristics, past medical history and care-seeking behaviour, and current clinical and laboratory data using standardized case report forms. Clinicians also recorded diagnoses and prescribed treatments. Children with any of the IMCI danger signs (unable to drink or breastfeed, convulsions, continuous vomiting, lethargy, and/or unconsciousness) were classified as having severe febrile illness [19]. All screened and enrolled children were tested for malaria using both smear microscopy and Paracheck $\mathrm{Pf}^{\oplus}$ RDTs (Orchid Biomedical Services, India). At each hospital, the same hospital microscopists prepared and read malaria slides. Malaria results were available to clinicians within 20-30 minutes of testing. These microscopists received no additional training before the study. Because causes of fever such as bacteraemia are associated with HIV [20] and malaria [21], children were tested for HIV using rapid antibody testing (Abbott Determine $^{\mathrm{Tm}}$ rapid test kit and confirmed using UniGold $\left.^{\mathrm{m}}\right)$ or PCR if child $\leq 18$ months. Finally, blood was cultured using BACTEC 9050 blood culture system, and pathogens were identified using a Microscan Walk away system. Results of the analyses of bacteremia data are presented elsewhere [22]. 


\section{Study outcomes}

Laboratory-confirmed malaria was defined as a positive smear microscopy and/or RDT test. Malaria overtreatment was defined as a negative smear and RDT result that was treated with anti-malarials.

\section{Statistical analysis}

Demographic, clinical and laboratory characteristics were compared between study sites using Chi-square or Fisher's exact tests for categorical variables and two sample t-tests or Wilcoxon rank sum tests for continuous variables.

The proportion of children laboratory-confirmed negative malaria but were treated with anti-malarials was estimated and compared between sites using Chisquare test. The association between malaria overtreatment (primary outcome) and patients' clinical and demographic characteristics that had been selected $a$ priori following a thorough literature review was first examined in a bivariate logistic regression. These included malnutrition, mother, and child's HIV status, presence of IMCI danger signs, fever of $\geq$ seven days, having previously sought care, pre-treatment with antimalarial prior to hospitalization. To identify independent correlates of malaria over-treatment, all of the following a priori selected confounders were included simultaneously in a multivariate logistic model: child's age, sex, whether the child was enrolled from out- or in-patient departments, primary caregiver's level of education and income. The latter two variables were used as surrogates for family socioeconomic status. Because the sites had marked differences in malaria endemicities that might impact clinician suspicion, analyses were stratified and compared by site. All analyses were done using Stata statistical software (version 13.1, Stata Corp, College Station, TX, USA). Strengthening the reporting of observational studies in epidemiology (STROBE) guidelines were followed in reporting this study [23].

\section{Results}

\section{Demographic, medical history and clinical characteristics}

Between April 2012 and November 2013, 1,362 febrile children were enrolled into the parent study; 685 in Kisii and 677 in Homa Bay. Figure 1 summarizes screening, enrolment, clinical treatment of malaria, and laboratory testing for malaria. Baseline demographic and clinical information of the enrolled children are shown in Table 1. Compared to children from Kisii, children from Homa Bay were younger, more likely to be female, more likely to be acutely malnourished (underweight), not to have received all age-appropriate vaccines, and sicker at presentation as defined by the presence of IMCI danger sign (s) $(52.6 \%$ vs $16.1 \%$; $<0.001)$. Children in Homa Bay were more likely to have HIV-infected mothers $(19.5 \%$ vs $3.3 \% ; \mathrm{p}<0.001)$ or to be HIV infected themselves (4.5\% vs $1.3 \%$; $\mathrm{p}<0.001)$ than those from Kisii. However, children from Homa Bay were less likely to be wasted, and to have previously sought health care elsewhere for their current illness than children from Kisii $(23.0 \%$ vs $33.9 \% ; \mathrm{p}=0.001$ ).

\section{Malaria diagnoses}

Among febrile children, 26\% had laboratory-confirmed malaria infection; $45.8 \%$ in Homa Bay and 6.7\% in Kisii; prevalence ratio $=6.82 ; 95 \%$ CI: 5.22-8.90. Among laboratory-confirmed malaria cases $(n=356), 96.1 \%$ were positive by both RDT and smear, 10 (2.8\%) were positive by RDT alone and $4(1.1 \%)$ were positive by smear alone. In Kisii, the prevalence of bacteraemia among children with and without malaria was $4.1 \%$ $(26 / 639)$ and $2.2 \%(1 / 46)$, respectively, $p=0.524$. The prevalence of bacteremia among children with and without malaria was $4.5 \%(45 / 1006)$ and $2.0 \%(7 / 35)$, respectively; $\mathrm{p}=0.034$.

\section{Malaria treatment and correlates of malaria over-treatment}

All children with laboratory-confirmed malaria $(\mathrm{n}=356)$ were treated with anti-malarials regardless of their initial provisional presumptive diagnosis. Most $(82.3 \%$ received artemisinin combination therapy (ACT), while $17.7 \%$ received quinine. Children treated with quinine were more likely than those treated with ACT to have danger sign(s) present 76.2\% (48/63) vs. 47.1\% (138/ 293); $\mathrm{p}<0.001$. Among children with laboratoryconfirmed negative malaria (639 in Kisii and 367 in Homa Bay), the proportion of those treated with antimalarials was significantly higher in Homa Bay as compared to Kisii $(57.2 \%$ vs. $7.0 \%$ p $<0.001)$. Overall, among those over-treated, children treated with quinine were more likely than those treated with ACT to have danger sign(s) present $76.2 \%$ (48/63) vs. $47.1 \%$ $(138 / 293) ; \mathrm{p}<0.001$.

Because the site characteristics and patients' demographic and clinical characteristics were so distinct, analyses were stratified and compared by site. In Kisii, odds of malaria over-treatment were significantly higher for children with high-grade fever (odds ratio $(\mathrm{OR})=2.14$; 95\% CI: 1.21-4.37), those who had taken anti-malarials in the week preceding hospitalization $(\mathrm{OR}=2.14 ; 95 \%$ CI: 1.03-4.44) and those whose mothers were HIVinfected $(\mathrm{OR}=3.26$; 95\% CI: 1.11-9.58) in bivariate analysis (Table 2). In multivariate analysis, only high-grade fever was associated with over-treatment $(\mathrm{aOR}=2.13$; 95\% CI: 1.02-4.45).

In Homa Bay, signs and symptoms of severe sickness were associated with over-treatment. The unadjusted odds of malaria over-treatment for children with both 


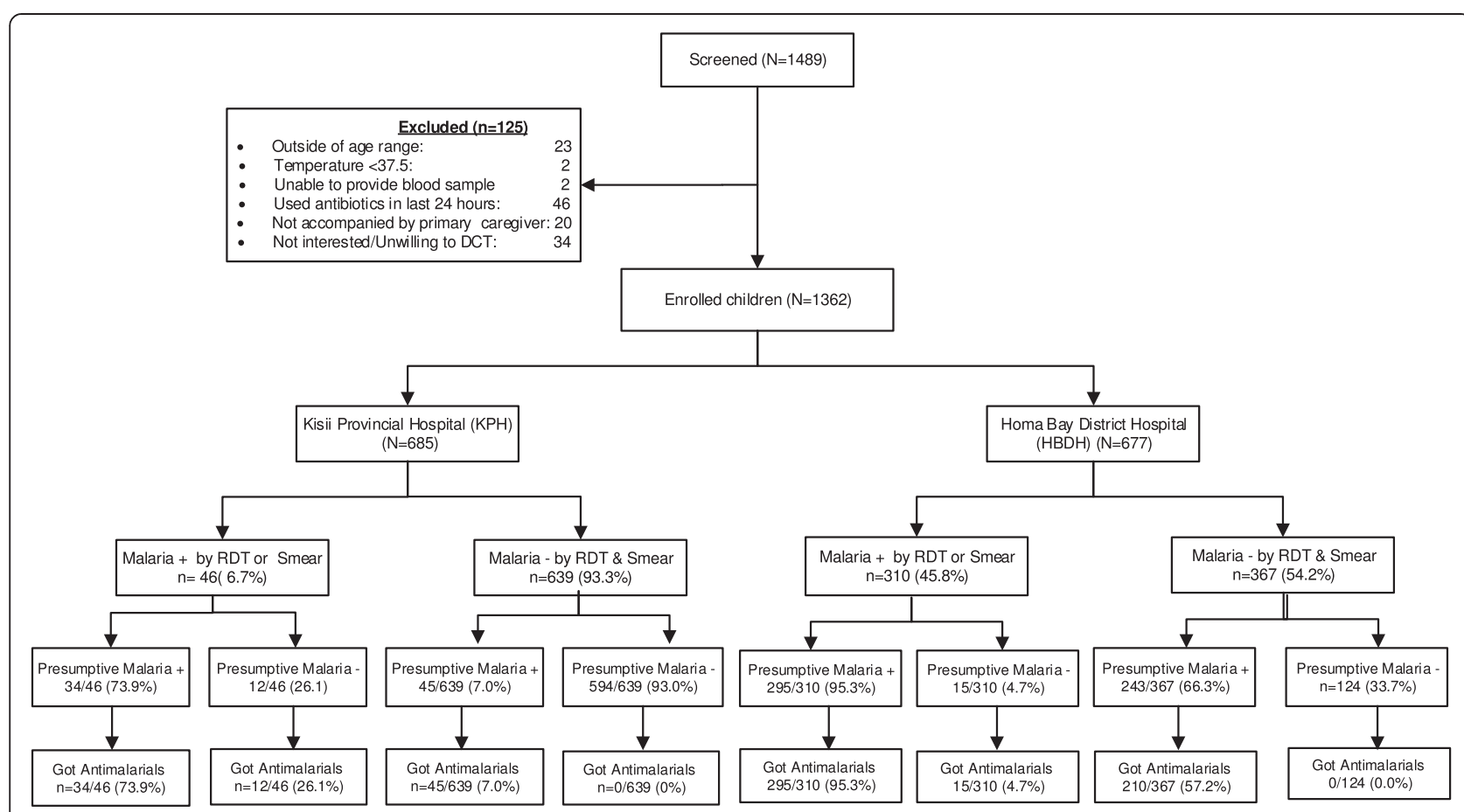

Figure 1 Flow chart showing enrolment of children by study site, laboratory, clinical diagnosis of malaria and treatment.

a negative blood smear and RTD test result were significantly higher for children with high-grade fever $(\mathrm{OR}=2.07 ; 95 \% \mathrm{CI}: 1.27-3.39)$, a history of fever lasting a week or more $(\mathrm{OR}=2.94 ; 95 \% \mathrm{CI}: 1.41-6.14)$, and at least one IMCI danger signs present $(\mathrm{OR}=5.78$; $95 \%$ CI: 3.66-9.14) (Table 3). However, the odds of overtreatment were lower for children who reported seeking care prior to current hospital visit (OR $=0.49 ; 95 \%$ CI: 0.30-0.79) and lower for children who had reported having taken antibiotics within the last one week $(\mathrm{OR}=0.42 ; \quad 95 \% \quad \mathrm{CI}:$ 0.18-0.98). These associations persisted and strengthened in multivariate logistic regression analyses adjusting simultaneously for $a$ priori selected confounders that included sex, age of the children, whether children were enrolled from inpatient or outpatient department, and primary caregivers' education and income. In multivariate analysis, malaria over-treatment in Homa Bay was significantly associated with high-grade fever $\geq 39^{\circ} \mathrm{C}(\mathrm{aOR}=3.07$; 95\% CI: 1.58-5.96), a history of fever lasting a week or more $(\mathrm{aOR}=4.98 ; 95 \% \mathrm{CI}: 1.90-12.80)$, and presence of at least one IMCI danger sign $(\mathrm{aOR}=8.47$; 95\% CI: 4.81-14.89). Notably, there was no significant association of malaria over-treatment with HIVinfection.

\section{Antibiotic treatment}

More children with negative laboratory malaria diagnostic tests were treated with both anti-malarials and antibiotics in Homa Bay than in Kisii (45.8 vs 6.3\%; $\mathrm{p}<0.001$ ). In Homa Bay, children more likely to be treated with both anti-malarials and antibiotics included those who presented with a history of fever lasting a week or more $(\mathrm{OR}=2.38$; $95 \% \mathrm{CI}: 1.09-5.20)$ or manifested an IMCI danger $\operatorname{sign}(\mathrm{s})(\mathrm{OR}=4.58$; $95 \%$ CI: 2.78-7.22). In Kisii, although children presenting with high-grade fever of $\geq 39^{\circ} \mathrm{C}$ but without malaria were more likely to receive both anti-malarials and antibiotics $(\mathrm{OR}=2.26$; 95\% CI: 1.22-4.16), the presence of IMCI danger signs was not predictive of dual treatment $(\mathrm{OR}=1.21$; 95\% CI: 0.55-2.69).

\section{Discussion}

Current malaria treatment guidelines recommend restricting anti-malarials to confirmed malaria cases only. This study assessed anti-malarial prescribing practices at two regional rural hospitals in western Kenya and found that malaria endemicity appears to be a major driver of clinicians' adherence to malaria laboratory test results.

Clinicians correctly adhered to positive test results and prescribed all malaria-positive children with antimalarials at both sites. However, more than half (57.2\%) of febrile children with laboratory-confirmed negative malaria in a high malaria transmission area were prescribed anti-malarials compared to only $7.0 \%$ in a low malaria transmission area. In Kisii, the only strong predictor of malaria over-treatment was a fever of $>39^{\circ} \mathrm{C}$. 
Table 1 Demographic and clinical characteristics of children by site

\begin{tabular}{|c|c|c|c|c|}
\hline \multirow{4}{*}{ Variable } & \multirow{4}{*}{$\begin{array}{l}\text { All sites } \\
n \% \\
n=1,362\end{array}$} & \multicolumn{2}{|l|}{ Study site } & \multirow{4}{*}{$\mathrm{p}$} \\
\hline & & Kisii & Homa Bay & \\
\hline & & n (\%) & n (\%) & \\
\hline & & $n=685$ & $n=677$ & \\
\hline \multicolumn{5}{|l|}{ Demographics } \\
\hline Child's sex: Female & $652(44.7)$ & $306(44.7)$ & $346(51.1)$ & 0.017 \\
\hline Age in years (Mean \pm SD) (Median) & $35.4 \pm 34(34)$ & $3.1 \pm 2.1(2.9)$ & $2.8 \pm 1.6(2.8)$ & 0.012 \\
\hline Age (years) & & & & $<0.001$ \\
\hline$\leq 2 \mathrm{yr}$ & $501(36.8)$ & $256(37.4)$ & $245(36.2)$ & \\
\hline $3-4 \mathrm{yr}$ & $721(53.0)$ & $335(49.0)$ & $386(57.1)$ & \\
\hline$\geq 5 \mathrm{yr}$ & $138(10.1)$ & $93(13.6)$ & $45(6.7)$ & \\
\hline Uses water from unimproved sources ${ }^{i}$ & $171(12.6)$ & $26(3.8)$ & $145(21.4)$ & $<0.001$ \\
\hline \multicolumn{5}{|l|}{ Primary caregiver's characteristics } \\
\hline Education & & & & $<0.001$ \\
\hline College/university & $159(11.7)$ & $101(14.8)$ & $58(8.6)$ & \\
\hline Secondary & $425(31.2)$ & $273(39.9)$ & $152(22.5)$ & \\
\hline At most primary & $777(57.1)$ & $310(45.3)$ & $467(69.0)$ & \\
\hline Monthly income & & & & $<0.001$ \\
\hline$\leq \$ 50$ & $550(40.4)$ & $189(27.6)$ & $361(53.3)$ & \\
\hline$\$ 50-100$ & $495(36.4)$ & $275(40.2)$ & $220(32.5)$ & \\
\hline$>\$ 100$ & $316(23.2)$ & $220(32.2)$ & $96(14.2)$ & \\
\hline \multicolumn{5}{|l|}{ Children's clinical presentations } \\
\hline \multicolumn{5}{|l|}{ Malnutrition } \\
\hline MUAC $<12.5$ & $40(2.9)$ & $15(2.2)$ & $25(3.7)$ & 0.087 \\
\hline Wasting $(\mathrm{WHZ}<-2)^{\mathrm{ii}}$ & $193(15.9)$ & $115(19.5)$ & $78(12.4)$ & 0.001 \\
\hline Stunted $(H A Z<-2)^{\mathrm{ii}}$ & $181(14.5)$ & $83(13.6)$ & $98(15.4)$ & 0.272 \\
\hline Underweight $(W A Z<-2)^{\text {iii }}$ & $127(10.2)$ & $52(8.5)$ & $75(11.8)$ & 0.044 \\
\hline Temperature $\left({ }^{\circ} \mathrm{C}\right)$ & & & & $<0.001$ \\
\hline $37.5-37.9$ & $205(15.1)$ & $138(20.1)$ & $67(9.9)$ & \\
\hline $38.0-38.9$ & $626(46.0)$ & $308(45.0)$ & $318(47.0)$ & \\
\hline 39.0-39.9 & $441(32.4)$ & $202(29.5)$ & $239(35.3)$ & \\
\hline$>=40.0$ & $90(6.6)$ & $37(5.4)$ & $53(7.8)$ & \\
\hline High grade fever $\left(>39^{\circ} \mathrm{C}\right)$ & $468(34.4)$ & $206(30.1)$ & $262(38.7)$ & 0.001 \\
\hline$\geq \mathrm{IMCl}$ danger sign(s) present ${ }^{\mathrm{iv}}$ & $466(34.2)$ & $110(16.1)$ & $356(52.6)$ & $<0.001$ \\
\hline Unable to drink/breastfeed & 198 & 14 & 184 & \\
\hline Vomits everything & 271 & 62 & 209 & \\
\hline Convulsions & 81 & 30 & 51 & \\
\hline Lethargic/unconscious & 113 & 43 & 70 & \\
\hline \multicolumn{5}{|l|}{ Past clinical history } \\
\hline Has had fever lasting $\geq 7$ days & & $263(38.4)$ & 79 (11.8) & $<0.001$ \\
\hline Sought healthcare elsewhere & $388(28.5)$ & $232(33.9)$ & $156(23.0)$ & $<0.001$ \\
\hline Taken anti-malarials last 7 days & $192(14.1)$ & $86(12.6)$ & $106(15.7)$ & 0.1000 \\
\hline Taken antibiotics last 7 days & $84(6.2)$ & $52(7.6)$ & $32(4.7)$ & 0.024 \\
\hline Not received all age-appropriate vaccines & $324(23.8)$ & $11(11.8)$ & $243(35.9 \%)$ & $<0.001$ \\
\hline
\end{tabular}


Table 1 Demographic and clinical characteristics of children by site (Continued)

\begin{tabular}{|c|c|c|c|c|}
\hline \multicolumn{5}{|l|}{ Laboratory results } \\
\hline \multicolumn{5}{|l|}{ Mother HIV -infected ${ }^{\vee}$} \\
\hline \multicolumn{5}{|l|}{ Child HIV-infected ${ }^{\mathrm{vi}}$} \\
\hline \multicolumn{5}{|l|}{ Malaria (smear or RDT) } \\
\hline Bacteraemia & $52(3.8)$ & $27(3.9)$ & $25(3.7)$ & 0.811 \\
\hline
\end{tabular}

iUnpiped water, unprotected boreholes, wells and springs, water from vendors.

iivalues outside plausible range for 95 children from Kisii and 50 from Homa Bay.

iii Values outside plausible range for 74 children from Kisii and 42 from Homa Bay.

iv Unable to feed/drink, vomits everything, convulsion, unconscious, stiff neck.

${ }^{\vee}$ Mother's HIV status unknown for 25 children from Kisii and 15 from Homa bay.

vi HIV status uknown for 15 children from Kisii and 3 from Homa Bay.

In Homa Bay, signs of more severe illness (high-grade fever $>39^{\circ} \mathrm{C}$, longer duration of fever, IMCI danger signs) were the strongest predictors of over-treatment with anti-malarials. In high malaria prevalence areas, clinicians may have over-treated sick children because they did not trust negative test results, and/or feared missing possible malaria cases, with potentially fatal consequences [24]. The finding that overtreatment is more common in an area of high malaria transmission is consistent with what might be expected: when prevalence of any disease is relatively high, a clinician's suspicion of the disease prior to testing is also high to avoid missing causes of disease that are common in a given area.

The higher proportion of children with danger signs in Homa Bay may, in part, reflect limited healthcare exposure, delayed access to, or poor engagement with, the health care system and inappropriate home treatment of children with fever. Additionally, significantly fewer children in Homa Bay (the high malaria risk area) had received all age-appropriate vaccines and children in Homa Bay were also significantly more likely to be HIV-infected or exposed. Because study procedures, inclusion criteria, and training of study clinicians were uniform across study sites, it is unlikely that the higher proportion of very sick children in Homa Bay was due to systematic selection bias or differential misclassification.

This study found that children exhibiting signs of severe disease were more likely to be treated for both malaria and for presumptive blood stream infection. More than $80 \%$ of the children at both sites were presumptively prescribed antibiotics. This suggests that in the absence of point-of-care diagnostics for other causes of fever, clinicians are reluctant to miss the opportunity to avert potential morbidity and mortality and will presumptively treat children, even when guidelines suggest otherwise. Malaria-negative

Table 2 Univariate and multivariate analysis of correlates of malaria over-treatment in Kisii

\begin{tabular}{|c|c|c|c|c|}
\hline \multirow[b]{3}{*}{ Potential correlates } & \multicolumn{2}{|l|}{ Over-treated } & \multirow{3}{*}{$\begin{array}{l}\text { Crude } \\
\text { cOR }(95 \% \mathrm{Cl})\end{array}$} & \multirow{3}{*}{$\begin{array}{l}\text { Adjusted }^{\S} \\
\text { aOR }(95 \% \mathrm{Cl})\end{array}$} \\
\hline & No $(n=594)$ & Yes $(n=45)$ & & \\
\hline & n (\%) & n (\%) & & \\
\hline \multicolumn{5}{|l|}{ Malnutrition } \\
\hline MUAC $<12.5$ & $13(2.2)$ & $1(2.2)$ & $1.02(0.13-7.94)$ & $1.57(0.18-13.42)$ \\
\hline Wasting & $107(20.8)$ & $5(14.3)$ & $0.64(0.24-1.68)$ & $0.70(0.20-1.89)$ \\
\hline Stunted & $73(13.7)$ & $3(8.6)$ & $0.59(0.18-1.98)$ & $0.75(0.18-3.01)$ \\
\hline Underweight & $45(8.4)$ & $2(5.7)$ & $0.66(0.15-2.83)$ & $1.12(0.18-7.12)$ \\
\hline Mother HIV-infected & $17(3.0)$ & $4(9.1)$ & $3.26(1.11-9.58)$ & $1.81(0.39-8.43)$ \\
\hline Child HIV-infected & $7(1.2)$ & $2(4.5)$ & $3.90(0.89-17.30)$ & $\mathrm{NA}^{+}$ \\
\hline Any IMCI danger sign? & $90(15.2)$ & $8(17.8)$ & $1.21(0.55-2.69)$ & $1.94(0.73-5.17)$ \\
\hline High grade fever $\left(>39^{\circ} \mathrm{C}\right)$ & $166(27.9)$ & $21(46.7)$ & $2.26(1.24-4.16)$ & $2.13(1.02-4.45)$ \\
\hline Fever for 7 or more days & $232(39.1)$ & $19(42.2)$ & $1.14(0.62-2.11)$ & $1.48(0.68-3.21)$ \\
\hline Sought care elsewhere & $195(32.8)$ & $14(31.1)$ & $0.92(0.48-1.78)$ & $0.83(0.33-2.06)$ \\
\hline Taken anti-malarial last 7 days & $70(11.8)$ & $10(22.2)$ & $2.14(1.03-4.44)$ & $2.45(0.84-7.29)$ \\
\hline Taken antibiotics last 7 days & $47(7.9)$ & $2(4.4)$ & $0.54(0.13-2.30)$ & $0.31(0.04-2.84)$ \\
\hline
\end{tabular}

${ }^{\dagger}$ Data insufficient to include this variable in multivariate model only two of the children over-diagnosed in Kisii were HIV+. ${ }^{5}$ Adjusted for child's age, sex, and caregivers' education and household income. 
Table 3 Univariate and multivariate analysis of correlates of malaria over-treatment in Homa Bay

\begin{tabular}{|c|c|c|c|c|}
\hline \multirow{3}{*}{$\begin{array}{l}\text { Variable } \\
\text { Potential correlates }\end{array}$} & \multicolumn{2}{|l|}{ Over-treated } & \multirow{3}{*}{$\begin{array}{l}\text { Crude } \\
\text { cOR }(95 \% \mathrm{Cl})\end{array}$} & \multirow{3}{*}{$\begin{array}{l}\text { Adjusted }^{\S} \\
\text { aOR }(95 \% \mathrm{Cl})\end{array}$} \\
\hline & No $(n=157)$ & Yes $(n=210)$ & & \\
\hline & n (\%) & n (\%) & & \\
\hline \multicolumn{5}{|l|}{ Malnutrition } \\
\hline MUAC $<12.5$ & $4(2.5)$ & $10(4.8)$ & $1.91(0.60-6.21)$ & $1.73(0.37-8.05)$ \\
\hline Wasting & $17(11.4)$ & $26(13.6)$ & $1.22(0.64-2.35)$ & $0.67(0.25-1.77)$ \\
\hline Stunted & $19(12.5)$ & $33(17.1)$ & $1.44(0.78-2.68)$ & $1.24(0.53-2.89)$ \\
\hline Underweight & $14(9.2)$ & $27(14.0)$ & $1.60(0.81-3.18)$ & $0.93(0.30-2.89)$ \\
\hline Mother HIV-infected & $30(19.2)$ & $45(22.0)$ & $1.18(0.70-2.00)$ & $1.19(0.59-2.50)$ \\
\hline Child HIV-infected & $6(3.9)$ & $15(7.1)$ & $1.90(0.72-5.01)$ & $1.36(0.35-5.27)$ \\
\hline Any $\mathrm{IMCl}$ danger sign? & $41(26.1)$ & $141(67.1)$ & $5.78(3.66-9.14)$ & $8.47(4.81-14.89)$ \\
\hline High grade fever $\left(>39^{\circ} \mathrm{C}\right)$ & $30(19.1)$ & $69(32.9)$ & $2.07(1.27-3.39)$ & $3.07(1.58-5.96)$ \\
\hline Fever for 7 or more days & $10(6.4)$ & $35(16.7)$ & $2.94(1.41-6.14)$ & $4.94(1.90-12.86)$ \\
\hline Sought care elsewhere & $48(30.6)$ & $37(17.6)$ & $0.49(0.30-0.79)$ & $0.32(0.18-0.63)$ \\
\hline Taken anti-malarial last 7 days & $26(16.6)$ & $50(23.8)$ & $1.57(0.93-2.67)$ & $1.95(0.95-4.00)$ \\
\hline Taken antibiotics last 7 days & $15(9.6)$ & $9(4.3)$ & $0.42(0.18-.98)$ & $0.17(0.05-0.55)$ \\
\hline
\end{tabular}

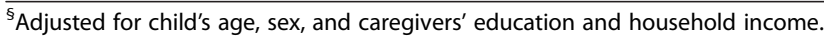

children were more likely to be prescribed antibiotics compared to children with positive results (93.3 vs. $58.2 \%, \mathrm{p}<0.001)$, suggesting that negative malaria test may have led clinicians to consider and treat alternative causes of fever.

The finding of significant malaria over-treatment, particularly in very sick children in endemic areas, is consistent with a recent Cochrane review of the effect of RDTs on the prescription of anti-malarials in Africa [24]. This review reported that underlying malaria prevalence influences clinicians' prescribing adherence to malaria test results. Findings from this study have important practical implications for regular refresher in-service trainings on importance of parasitologicalsupported malaria treatment, and structured supervision of clinicians to increase their adherence to "test and treat" policy as well as their confidence in malaria test results. Given the concern of missing possible malaria infections, training should reiterate findings from multiple trials which have shown that although RDTs may miss some uncomplicated malaria infections, these are mainly low-density and self-limiting infections, which rarely develop into severe malaria [25]. The finding that very sick-looking children were treated with anti-malarials despite negative laboratory tests suggests the need to educate clinicians that withholding anti-malarials from febrile malaria-negative patients is clinically safe, even in endemic areas [24-27]. Because malaria tests, particularly RDTs, may be the only diagnostic tools routinely available in rural areas in Kenya, it is necessary to train, support, and supervise clinicians on the use of test result as basis for prescribing anti-malarials, and that a negative test should prompt an assessment and treatment of the true causes of fever.

While this study had several strengths, notably the inclusion of data from two sites in Kenya with widely differing underlying malaria endemicity, there were also some weaknesses. Malaria over-treatment was only evaluated in relation to patients' demographic and their clinical symptoms. Other factors such as clinicians' level of training, number of clinical staff and patient load, patients' expectations, diagnostic laboratory capacity, and regular supervision and public health promotional activities also likely affect clinicians' malaria diagnosis and treatment decisions. Lastly, although the inclusion of only children with fever $\geq 37.5^{\circ} \mathrm{C}$ was intended to enhance the clinical yield of microbiologic investigations, this may limit the generalizability.

\section{Conclusions}

Febrile patients, particularly those with signs of more severe illness in areas of high malaria transmission, continue to be treated with anti-malarials despite negative laboratory tests, against current WHO "test-treat" policy. This may result in missed opportunities to accurately diagnose and treat alternative causes of fever. There is need for the strengthened training in fever case management, supervision, monitoring and evaluation of malaria treatment practices by clinicians in order to ensure adherence to malaria test results, particularly in areas of high malaria endemicity. 


\section{Competing interests}

The authors declare that they have no competing interests.

\section{Authors' contributions}

FMO conceived the research idea, assembled the data, performed the analysis, interpreted the analysis results and wrote and reviewed the paper with contributions from all the co-authors. PBP participated in the data collection and management, analysis and interpretation, writing, critical review and revision of the paper. BSO and JNM participated in study implementation, data collection and clinical management of the children and reviewed the paper. EO was the laboratory manager and participated in study implementation, ran laboratory tests and reviewed the paper. BAR and CF participated in the conception of the research idea, supervised its analysis and interpretation, and critically reviewed and revised the paper. GJS and JLW conceived, designed and supervised the study implementation and participated extensively in the writing and the review of this paper. All authors discussed the results and commented on the manuscript at all stages, and gave final approval of the version to be published.

\section{Acknowledgements}

We thank all of the participants and the hospitals that participated in this study. We acknowledge the staff of the KEMRI/University of Washington collaboration, and the US Army Medical Research Unit in Kenya (USMRU-K). We thank Kizazi working group (UW Global Center for Integrated Health of Women, Adolescents and Children (Global WACh) and the Kenya Research Programme for their support during the preparation of this article. The findings and conclusions in this paper are those of the authors and do not necessarily reflect the official views of their supporting institutions. The manuscript is submitted for publication with the permission of the Director Kenya Medical Research Institute (KEMRI). This work was supported by the National Institute of Health (NIH) grant numbers U19-A2090882 and D43TW000007 to the University of Washington. FMO was also supported by the Northern Pacific Global Health Fellows Training Consortium sponsored by the National Institutes of Health's Fogarty International Center (FIC) grant number R25TW009345. PP is supported by the University of Washington STD/AIDS Research Training Program, (Grant number T32-Al007140) from the National Institutes of Health. GJS is supported by a National Institute of Health mentoring award (grant number K24-HD054314). The content of this manuscript is solely the responsibility of the authors and does not necessarily represent the official views of the $\mathrm{NIH}$.

\section{Role of the funding source}

The study's sponsors had no role in study design, the collection, analysis, interpretation of data, or manuscript preparation. FMO had full access to all the study data and had final responsibility for the decision to submit manuscript for publication.

\section{Author details}

${ }^{1}$ Department of Epidemiology, University of Washington, 325 Ninth Avenue, Box 359909, Seattle, WA 98104, USA. ${ }^{2}$ Kenya Medical Research Institute, Centre for Clinical Research, Nairobi, Kenya. ${ }^{3}$ Department of Pediatrics, University of Washington, Seattle, USA. ${ }^{4}$ Department of Biostatistics, University of Washington, Seattle, USA. ${ }^{5}$ Department of Global Health, University of Washington, Seattle, USA. ${ }^{6}$ Department of Medicine, University of Washington, Seattle, USA. Vaccine and Infectious Disease Division, Fred Hutchinson Cancer Research Center, Seattle, USA. ${ }^{8}$ Walter Reed Project, United States Army Medical Research Unit, Kericho, Kenya.

Received: 10 September 2014 Accepted: 13 February 2015 Published online: 01 March 2015

\section{References}

1. UNICEF: Malaria: A major cause of child death and poverty in Africa [http:// www.unicef.org/publications/files/malaria_rev_5296_Eng.pdf] UNICEF Roll Back Malaria; 2004

2. WHO. Informal Consultation on fever management in peripheral health care settings: a global review of evidence and practice. 2013. http://www.who. int/malaria/mpac/who_consultation_fever_management_presentation.pdf. [Accessed on 01/03/2014]
3. D'Acremont V, Lengeler C, Genton B. Reduction in the proportion of fevers associated with Plasmodium falciparum parasitaemia in Africa: a systematic review. Malar J. 2010;9:240.

4. Gething PW, Kirui VC, Alegana VA, Okiro EA, Noor AM, Snow RW. Estimating the number of paediatric fevers associated with malaria infection presenting to Africa's public health sector in 2007. PLoS Med. 2010;7:e1000301.

5. O'Meara WP, Mangeni JN, Steketee R, Greenwood B. Changes in the burden of malaria in sub-Saharan Africa. Lancet Infect Dis. 2010;10:545-55.

6. Crump JA, Morrissey AB, Nicholson WL, Massung RF, Stoddard RA, Galloway $R L$, et al. Etiology of severe non-malaria febrile illness in Northern Tanzania: a prospective cohort study. PLoS Negl Trop Dis. 2013;7:e2324.

7. Gwer S, Newton CR, Berkley JA. Over-diagnosis and co-morbidity of severe malaria in African children: a guide for clinicians. Am J Trop Med Hyg. 2007;77:6-13.

8. Reyburn H, Mbatia R, Drakeley C, Carneiro I, Mwakasungula E, Mwerinde O, et al. Overdiagnosis of malaria in patients with severe febrile illness in Tanzania: a prospective study. BMJ. 2004;329:1212.

9. WHO. Guidelines for the treatment of malaria. 2nd ed. Geneva, Switzerland: World Health Organization; 2010.

10. Zurovac D, Githinji S, Memusi D, Kigen S, Machini B, Muturi A, et al. Major improvements in the quality of malaria case-management under the "test and treat" policy in Kenya. PLoS One. 2014;9:e92782.

11. Juma E, Zurovac D. Changes in health workers' malaria diagnosis and treatment practices in Kenya. Malar J. 2011;10:1.

12. Zurovac D, Njogu J, Akhwale W, Hamer DH, Larson BA, Snow RW. Effects of revised diagnostic recommendations on malaria treatment practices across age groups in Kenya. Trop Med Int Health. 2008;13:784-7.

13. Evans JA, Adusei A, Timmann C, May J, Mack D, Agbenyega T, et al. High mortality of infant bacteraemia clinically indistinguishable from severe malaria. QJM. 2004;97:591-7.

14. Amexo M, Tolhurst R, Barnish G, Bates I. Malaria misdiagnosis: effects on the poor and vulnerable. Lancet. 2004;364:1896-8.

15. Osei-Kwakye K, Asante KP, Mahama E, Apanga S, Owusu R, Kwara E, et al. The benefits or otherwise of managing malaria cases with or without laboratory diagnosis: the experience in a district hospital in Ghana. PLoS One. 2013;8:e58107.

16. Zhong D, Afrane Y, Githeko A, Yang Z, Cui L, Menge DM, et al. Plasmodium falciparum genetic diversity in western Kenya highlands. Am J Trop Med Hyg. 2007;77:1043-50.

17. Beier JC, Oster CN, Onyango FK, Bales JD, Sherwood JA, Perkins PV, et al. Plasmodium falciparum incidence relative to entomologic inoculation rates at a site proposed for testing malaria vaccines in western Kenya. Am J Trop Med Hyg. 1994;50:529-36.

18. Zhou G, Afrane YA, Vardo-Zalik AM, Atieli H, Zhong D, Wamae P, et al. Changing patterns of malaria epidemiology between 2002 and 2010 in Western Kenya: the fall and rise of malaria. PLoS One. 2011;6:e20318.

19. HandBook of WHO/UNICEF guidelines for Integrated Management of Childhood IIIness (IMCI). (http://whqlibdoc.who.int/publications/2005/ 9241546441.pdf)

20. Berkley JA, Lowe BS, Mwangi I, Williams T, Bauni E, Mwarumba S, et al. Bacteremia among children admitted to a rural hospital in Kenya. N Engl J Med. 2005;352:39-47.

21. Scott JAG, Berkley JA, Mwangi I, Ochola L, Uyoga S, Macharia A, et al. Relation between falciparum malaria and bacteraemia in Kenyan children: a population-based, case-control study and a longitudinal study. Lancet. 2011;378:1316-23.

22. Onchiri FM, Patricia P, Singa BO, Naulikha JM, Odundo E, Carey F, Richardson BA, John-Stewart G, Walson JL. Bacteremia Among Febrile Children in Areas of Differing Malaria Transmission in Rural Kenya: A Prosepective Cross-sectional study. MS ID: JPIDS-2015-008

23. von Elm E, Altman DG, Egger M, Pocock SJ, Gotzsche PC, Vandenbroucke $J P$. The Strengthening the reporting of observational studies in epidemiology (STROBE) statement: guidelines for reporting observational studies. J Clin Epidemiol. 2008;61:344-9.

24. Odaga J, Sinclair D, Lokong JA, Donegan S, Hopkins H, Garner P. Rapid diagnostic tests versus clinical diagnosis for managing people with fever in malaria endemic settings. Cochrane Database Syst Rev. 2014:4:CD008998.

25. Bjorkman A, Martensson A. Risks and benefits of targeted malaria treatment based on rapid diagnostic test results. Clin Infect Dis. 2010;51:512-4. 
26. d'Acremont V, Malila A, Swai N, Tillya R, Kahama-Maro J, Lengeler C, et al. Withholding antimalarials in febrile children who have a negative result for a rapid diagnostic test. Clin Infect Dis. 2010;51:506-11.

27. Njama-Meya D, Clark TD, Nzarubara B, Staedke S, Kamya MR, Dorsey G.

Treatment of malaria restricted to laboratory-confirmed cases: a prospective cohort study in Ugandan children. Malar J. 2007;6:7.

Submit your next manuscript to BioMed Central and take full advantage of:

- Convenient online submission

- Thorough peer review

- No space constraints or color figure charges

- Immediate publication on acceptance

- Inclusion in PubMed, CAS, Scopus and Google Scholar

- Research which is freely available for redistribution 